\title{
Predictive model of effective sustainable operation for sustainable development of enterprises
}

\author{
Haitong Wang ${ }^{1, \mathrm{a}}$, Ziyi Cheng ${ }^{2, \mathrm{~b}}$, Hongyan $\mathrm{Li}^{2, \mathrm{c}}$ \\ ${ }^{1}$ International Business School, Shanxi Normal University, Xi'an, China \\ ${ }^{2}$ International Business School, Shanxi Normal University, Xi'an, China
}

\begin{abstract}
Business forecasting has a very important impact on the future development of listed companies. Especially in the current era of information, corporate financial information disclosure is more comprehensive, so a reasonable business forecasting model is particularly important in the market. For the study of business operation forecasting models, Chinese scholars have achieved relevant results. This article is mainly based on the existing models for innovation and development. By establishing two models, SR + CART and ANN + CART, and testing their prediction accuracy, it provides a more diverse and reasonable tool for business forecasting, which is beneficial to the efficient development of capital market. The results show that the ANN + CART model has higher prediction accuracy, and the overall prediction accuracy is $92 \%$.
\end{abstract}

\section{Introduction}

The going concern forecast is the key link for listed companies to be able to continue operating in the market to obtain economic benefits. Business forecasting is mainly based on the auditor's or certified public accountant's auditing of the company's financial statements, combined with its own experience and forecasting tools, to determine whether the company can continue to produce and related capital operating activities on the existing scale of operations. In the era of information the business forecast of an enterprise can have a significant impact on the development of the enterprise itself. First, the certified public accountant combined with the company's financial statements and other materials that can reflect the company's operating conditions, and concluded whether the company can continue to operate or go bankrupt. If the company can continue to operate and generate economic benefits in the next ten years under the existing market size and capital conditions, the CPA will give an unqualified conclusion. The sustainable operation of the enterprise will bring huge economic benefits to the enterprise, and relevant stakeholders and market capital will further invest in the enterprise, which will play an important role in promoting the future development of the enterprise. If a business is at risk of bankruptcy in the foreseeable future, the CPA will give a conclusion. Such a conclusion will also have a significant impact on the enterprise, meaning that the enterprise does not have the characteristics of continuous operation in the future, or even goes bankrupt, which is a huge loss to relevant stakeholders and corporate capital. Generally speaking, if such a conclusion is issued, the relevant stakeholders will reduce or even stop investing in the company, which will affect the company's sustainable operating ability.

In the context of informatization development, the conclusions of a certified public accountant or auditor on a company's sustainable management forecast will have an important impact on the future development of the company. Up to now, the market economy has developed qualitative forecasting and quantitative forecasting. Qualitative forecasting is based on a company's financial statements and a combination of past experience with a certified accountant or auditor. This kind of prediction has certain subjectivity and has important influence on the judgment of the CPA himself. Generally, a certified public accountant will give an objective and evidencebased conclusion that is worthy of the trust of stakeholders and the market. However, if the certified public accountant fails to give a correct judgment on continuing operations, it will have a significant impact on the company or stakeholders. In individual cases, CPAs may be suspected of fraud. For example, an enterprise may go bankrupt in the future, collude with a certified public accountant, and give the opposite conclusion of continuing operations. The certified public accountant may also make subjective mistakes in the prediction of the company's sustainable operation, thus giving wrong audit results. No matter what happens, it is extremely detrimental to the sustainable operation and market development of the enterprise. Quantitative forecasting means that the manager formulates a suitable model formula in advance, and brings the results of the business forecast into the model based on the relevant data of the

a1219769143@qq.com, bczy@snnu.edu.cn, c2585941175@qq.com 
business operation. This method is scientific and practical. Managers need to first bring into the model to select explanatory variables with high relevance based on past data. These variables have an important impact on the company's future business forecasts. The variable data is brought into the model to draw conclusions. Quantitative forecasting uses a large amount of data on the operation of the enterprise. The selected variables have a relatively comprehensive and objective impact on the operation forecast of the enterprise. Under normal circumstances, the innovation drive of an enterprise will also affect the final business forecast. With the rapid development of information technology, the mechanization of enterprises has become more and more common, which will also have a certain impact on the profitability of enterprises. The forecast can more objectively and accurately draw the forecast results of the future sustainable operation of the enterprise.

Regarding research on business forecasting, Altman and McGough (1974) and McKeown, Mutchler, and Hopwood (1991) innovatively link the audit judgment of continuing operations suspicion with business failure prediction. Altman and McGough compared the Z-score statistical forecasting model of Altman (1968) and the auditor's ability to predict the company's suspicion of continuing operations in the event of a company failure. Therefore, it is recommended that auditors use statistical forecasting models to improve the accuracy of audit decisions. Other researchers have also concluded that statistical prediction models are more accurate than auditors' judgments (Levitan and Knoblet 1985; Koh and Killough 1990; Koh 1991). In addition, a report issued by the Cohen Committee (AICPA, 1978) found that the accuracy of the company's business forecasting model is higher than the auditor's judgment of continuing operations doubt. The International Federation of Accountants requires certified accountants to pay as much attention to this issue as possible when announcing doubts about the continuing operations of the companies being investigated. Although these suggestions imply that although the CPA will combine his own experience and comprehensive and objective financial information of the company, the reasonableness of his audit judgment is questioned. Therefore, combining objective business forecasting tools will provide reasonableness for the audit results of the CPA, so that it's accuracy is improved.

Chinese scholars have three main research tools for business operation forecasting: logistic regression models, artificial neural networks, and decision tree algorithms. The related research of logistic regression model started in the 1980s, and got some research results. At present, scholars' prediction tools for business operations are mainly artificial neural networks and decision trees. Generally, decision tree algorithms can obtain more accurate and valuable conclusions in the operation forecast of enterprises.

This paper is based on the use of quantitative analysis tools for business operations forecasting. First, logistic regression and artificial neural networks are used to bring in data to obtain highly relevant variables that affect the continuous operation of the company. Then these variables are brought into the decision tree model. To get the business operation forecast model, the purpose is to establish an effective and innovative business operation forecasting tool, which is of great significance to the company's future strategy formulation and market development.

\section{Model settings and data sources}

\subsection{Model Setting}

SR is a traditional and commonly used statistical method. In terms of data mining technology, the operation of artificial neural networks is similar to biological neurons. Through continuous learning and correction of data, the correct statistical analysis method is obtained. Artificial neural networks have the following advantages and characteristics:

- self-learning ability: can independently learn rules or models hidden in the input data;

- fault tolerance: the learned rules or models are scattered in In the entire network, which causes damage to a small part of the neural network, the network has little effect on the performance of the system;

- Parallel processing capabilities: suitable for processing many complex non-linear problems;

- $\quad$ self-tuning capabilities: according to the new Input materials adjust learned rules or models.

Decision tree algorithm has a very wide application in the field of data mining, and it is a particularly effective method for solving classification problems. Decision tree is a simple inductive learning method. It is mainly used to classify known facts, summarize related judgment rules, and build a tree structure diagram. That is, by continuously classifying different features of the selected data and calculating different contribution values of each feature, a decision tree with the best rules is generated. In addition to easy-to-understand graphical analysis results, decision trees have the following advantages (Quinlan 1986):

- Decision tree models can be represented by graphs or rules, and these rules are easy to interpret and understand;

- It can handle continuous or Class variables, revealing the relative importance of variables;

- It can handle large data sets, that is, when multiple variables are input into the model, a decision tree can construct them.

The decision tree algorithm used in this study is CART, which is described as follows:

CART is a technique for generating a binary tree. It uses the Gini index as the basis for selecting attributes. The biggest feature of the CART algorithm is that each node uses a binary method to cut the data set into two subsets and repeats the calculation until a complete tree structure is constructed. The CART algorithm detects whether the data in each node belongs to the same 
category. If there are no different categories, stop cutting. If more than two categories still exist in a node, the node is continuously cut. The algorithm will test all data attributes, divide the data into two subsets according to the attributes, and divide the Gini index as an evaluation index according to each attribute to be used. When the Gini index is small, it indicates that the category purity of the subset generated by the cut point is higher, and the judgment ability of the cut point is better. The Gini index is calculated as follows:

$\operatorname{Gini}(A)=1-\sum_{a-1}^{n} p_{a}^{2}$

A: indicates a specific node

$\mathrm{Pa}$ : represents the probability of different classes in node $\mathrm{A}$

In addition, in order to ensure that no fit occurs during data cutting, CART will first grow the tree structure to the upper limit, and then delete a small part from the terminal of the prediction perspective.

In the selection of the core explanatory variables, the practice of Chen(2019) was borrowed. The core variables that affect the business forecast of the enterprise were selected through two methods of stepwise regression (SR) and artificial neural network. The specific variable information is as follows:

TABLE I.

SR AND ANN SELECTION RESULTSS

\begin{tabular}{|c|l|l|}
\hline Model & SR selection result & $\begin{array}{l}\text { ANN selection } \\
\text { result }\end{array}$ \\
\hline $\mathbf{a}$ & $\begin{array}{l}\text { Sales revenue } \\
\text { growth rate }\end{array}$ & Pre-tax profit ratio \\
\hline $\mathbf{b}$ & Inventory turnover & Current ratio \\
\hline $\mathbf{c}$ & $\begin{array}{l}\text { Operating cash flow } \\
\text { ratio }\end{array}$ & $\begin{array}{l}\text { Net income/Total } \\
\text { assets }\end{array}$ \\
\hline $\mathbf{d}$ & $\begin{array}{l}\text { Net income/Total } \\
\text { assets }\end{array}$ & $\begin{array}{l}\text { (Natural logarithm } \\
\text { of operating income }\end{array}$ \\
\hline $\mathbf{e}$ & Current ratio & $\begin{array}{l}\text { Sales revenue } \\
\text { growth rate }\end{array}$ \\
\hline $\mathbf{f}$ & $\begin{array}{l}\text { Change CPA } \\
\text { firm(CPAS)or not }\end{array}$ & $\begin{array}{l}\text { Inventory/Total } \\
\text { assets }\end{array}$ \\
\hline $\mathbf{g}$ & $\begin{array}{l}\text { Natural logarithm of } \\
\text { operating income }\end{array}$ & $\begin{array}{l}\text { Accounts receivable } \\
\text { turnover }\end{array}$ \\
\hline h & Quick ratio & $\begin{array}{l}\text { Change CPA } \\
\text { firm(CPAS)or not }\end{array}$ \\
\hline
\end{tabular}

It can be seen from the table that in the SR regression model and the neural network model, there are eight main factors that affect the financial status of the company. From the above data, we can see that the Sales revenue growth rate.Net income/Total assets. Current ratio. Change CPA firm(CPAS)or not. Natural logarithm of operating income are the most important indicators that affect corporate finance, and these indicators are indeed the most important indicators that reflect the company's solvency, growth and profitability. It can be seen that the model has good predictions and analysis ability

\subsection{Data Sources}

In this article, 110 listed companies in China's securities market from 2006 to 2015 were used as sample data. The data are all from the website of the China Securities Regulatory Commission and the GF Securities trading platform. In addition, the following two points need to be explained about the setting and selection of data:

Among the selected listed companies, there are companies that have been judged to be "abnormal financial status" due to the financial crisis. In this article, ST is indicated. There are also listed companies that are in good financial condition and are judged to be able to continue operating. In addition, in order to avoid other factors affecting the operating forecasts of listed companies, the text will exclude financial companies.

The data in this article uses the method of sample matching. Among the 110 listed companies, 80 companies are used as sample groups, of which 40 are companies with good operating conditions and no doubt about continuing operations, 40 are ST companies, and 30 are other companies. As a control group, 15 of them were ST companies and the other 15 were not ST companies. Use the past financial data of 80 listed companies to build a model, and then bring the relevant data of 30 companies in the control group into the prediction accuracy of the test model.

\section{Regression results and discussion}

This article uses data from the China Securities Regulatory Commission's website and the GF Securities Trading Platform to take the 8 financial indicators selected by the aforementioned SR and ANN models as input variables (independent variables), and whether the listed company has been ST as the target variable (dependent variable). ), In the parameter setting, set the value of the "other processing" variable of the ST company to 1 , and the value of the "special processing" variable of the non-ST company to 0 , and then use the CART algorithm to establish and operate a prediction model. Based on the analysis of the prediction results of each model, the correlation and degree of correlation between the characteristics of each financial indicator and the continuous operation of listed companies can be discovered.

By establishing SR + CART and ANN + CART business forecasting models, and using the financial data of 30 listed companies in the control group to bring in the model, the test results obtained are compared with the actual situation. Finally, the test accuracy of the two models is as follows:

TABLE II. PREDICTION ACCURACY OF SR AND ANN

\begin{tabular}{|l|l|}
\hline Model & Prediction accuracy \\
\hline Sr+Cart & $88.56 \%$ \\
\hline $\begin{array}{l}\text { Ann+Ca } \\
\text { rt }\end{array}$ & $92.81 \%$ \\
\hline
\end{tabular}


The test result of the SR + CART model has a prediction accuracy of $88.56 \%$ and a high correct detection rate. When the SR + CART model predicts 15 ST companies, there are 13 listed companies that are correctly detected by the SR + CART model, and the detection results of 2 companies are inconsistent with the actual. When predicting 15 companies that are not ST, there are 14 judgments were correct and one judgment was wrong.

The detection result of the ANN + CART model has a prediction accuracy of $92.81 \%$. When the ANN + CART model predicts $15 \mathrm{ST}$ companies, the model can predict 14 correct companies, and 1 company fails to predict the correct results. When predicting 15 companies that are not ST, there are also 14 enterprises that are judged correctly and one enterprise is judged wrongly.

Through the appeal analysis, the conclusion of this article is that the SR + CART model and ANN + CART model have good effects in the business forecast of listed companies, and the prediction accuracy rate is above $80 \%$. Relatively speaking, the accuracy of ANN + cart model is higher, which can reach $90 \%$.

\section{Conclusions}

This article uses the corporate data provided by the Chinese securities market to estimate the sample of past financial data of 80 listed companies with the same industry and similar asset size, and then brings these data into the decision tree algorithm CART model to establish a business forecasting model. Then the relevant data of 30 listed companies in the control group were brought into the two models to test the prediction accuracy of the models. It was found that the prediction accuracy of the SR + CART model was $88.56 \%$, and the prediction accuracy of the ANN + CART model was $92.81 \%$. Both models have higher prediction accuracy, which is of higher significance for corporate strategy formulation and market development, but the prediction accuracy of ANN + CART is higher, indicating that the prediction results of the ANN + CART model are more convincing.

Many financial crises are symptomatic and can be prevented in advance. Through the establishment and testing of the two models, the business forecasting model of the enterprise can be further innovatively developed. For the enterprise, it is necessary to continue to pay attention to the impact of the surrounding environment such as itself and the market on the future development of the enterprise. In order to prevent enterprises from being suspected of bankruptcy, taking proactive measures and establishing a complete operation management mechanism and early warning system are of great significance to the healthy and sustainable development of enterprises.

\section{References}

1. Chen. An effective going concern prediction model for the sustainability of enterprises and capital market development[J]. Applied Economics,2019,51(31).

2. Fernando,Li,Hou. Corporate governance and default prediction: a reality test $[\mathrm{J}]$. Applied Economics,2019,51(24).

3. Cory M. Krause,Lei Zhang. Short-term travel behavior prediction with GPS, land use, and point of interest data[J]. Transportation Research Part B,2019,123.

4. Chung-Ching Tai,Hung-Wen Lin,Bin-Tzong Chie,Chen-Yuan Tung. Predicting the failures of prediction markets: A procedure of decision making using classification models[J]. International Journal of Forecasting,2018.

5. Lean Yu,Yaqing Zhao,Ling Tang,Zebin Yang. Online big data-driven oil consumption forecasting with Google trends[J]. International Journal of Forecasting,2017.

6. Joyce $\mathrm{P}$ Jacobsen,Laurence M Levin,Zachary Tausanovitch. Comparing Standard Regression Modeling to Ensemble Modeling: How Data Mining Software Can Improve Economists' Predictions[J]. Eastern Economic Journal,2016,42(3).

7. Onukwugha Eberechukwu,Qi Ran,Jayasekera Jinani,Zhou Shujia. Cost Prediction Using a Survival Grouping Algorithm: An Application to Incident Prostate Cancer Cases.[J]. PharmacoEconomics,2016,34(2). 